\title{
Managing the Formation of The Individual Financial Culture of University Students
}

\author{
Galina Borisovna Andreeva ${ }^{1 *}$, Olga Alekseevna Nikitina ${ }^{1}$, Lyudmila Vladimirovna Pavlova ${ }^{2}$ \\ and Elena Aleksandrovna Sokolova ${ }^{1}$ \\ ${ }^{1}$ The Academy of the FPS of Russia, The Institute of the Academy of the FPS of Russia, Ryazan, \\ Russia \\ ${ }^{2}$ Research Institute of the Federal Penitentiary Service of Russia, Research center-2, Moscow, Russia
}

\begin{abstract}
The purpose of the study dealing with the mechanisms for managing the formation of the individual financial culture of university students is to identify the optimal pedagogical conditions that contribute to the development of financially literate behavior of students studying under education agreements as rational consumers of educational services. The work performed allowed concluding that the attitude of students to mastering the chosen educational program, their academic performance, as well as social and labor activity allows predicting the nature of their financial behavior as market actors in their future daily life. The majority of students do not tend to treat their training as an investment in their own human capital due to the predominance of paternalistic attitudes associated with the imposition of costs for education on older family members.
\end{abstract}

\section{Introduction}

The issue of the current research is to identify the relationship between the academic behavior of students as consumers of educational services and models of their individual financial culture, as well as to search for mechanisms influencing the model components.

In the current context of economic development, characterized by high instability and uncertainty, the study of the financial culture phenomenon of the individual becomes particularly relevant and acts as the most important managerial task, whose solution allows determining the development vectors of the financial market of the state in general.

The theoretical basis of the research includes the works of domestic and foreign authors in the field of financial behavior, determining causes and conditions, which concern both subjective factors, including psychological characteristics of the individual [1,2], religion [3], financial confidence [4], satisfaction with relationships with a partner [5], the practice of experiencing financial threats [6], trust in state financial institutions [7], self-control skills [8], as well as objective circumstances, such as the place of residence [9], and the tax policy of the state [10].

The purpose of the study is to reveal typical patterns of the individual financial culture of student youth, as well as the mechanisms of their formation and correction based on the

\footnotetext{
* Corresponding author: g.b.andreeva@mail.ru
} 
analysis of the educational behavior of students, and their various activities in extracurricular areas. The goal is achieved by solving the following main tasks: identifying the main elements of students' financial culture, indicators, and levels of its formedness; evaluating the potential of students' volunteer activities in developing their financial culture; analysis of pedagogical conditions of the individual financial culture formation and development in the course of educational activities.

\section{Methods}

At the first stage of the experimental work, students were surveyed to identify the qualitative characteristics of their financial culture. Mastering of higher education programs by students based on agreements on the provision by the university of paid educational services allows considering the choice of the university and the educational program a financial choice of the student in the capacity of the consumer.

The research is based on surveying the students of the Institute for Training State and Municipal Employees of the Academy of the Federal Penitentiary Service of Russia where more than 1,500 full-time and part-time students are currently studying. The survey was attended by 3-4-year students who were studying full-time in the educational programs of Bachelor's degrees (40.03.01 Law) and Specialist's program (38.05.01 Economic Security) aged 20 to 23 years. Among the respondents, 58\% of students lived in the administrative centers of the Russian Federation before entering the Academy, while 42\% lived in regional level localities.

The experimental hypothesis is as follows: forming and developing an individual financial culture of students will be effective if the following conditions are met: high academic performance of students in the studied disciplines; involvement of students in volunteer activities in the field of financial literacy and financial control; and the reasonable competent employment during the study period at the university.

The level of formedness of the financial culture of students is characterized by the quality of financial and legal knowledge, the nature of students' behavior as consumers of paid educational services, as well as individual financial discipline concerning compliance with the terms of the agreement on education.

\section{Results}

The majority of respondents $(68 \%)$ rated their level of financial literacy as average, while almost one in three respondents $(29 \%)$ considered their level of financial literacy to be high or above average.

When evaluating the choice made in favor of paid education, the equal number of respondents $(50 \%)$ noted that it was informed choice (they were interested in this particular university, but did not want to be a cadet; parents expressed their readiness to pay for education at any university of the applicant's choice), and forced-choice (the specialty they were interested in was not state-funded; was not admitted to a state-funded place).

A significant part of respondents $(76 \%)$ rated their academic performance as quite high (either with good or excellent marks), while $21 \%$ of respondents indicated that they studied mainly with excellent marks. The self-assessment of students' performance was confirmed by the results of the examination sessions: the average score of those who took part in the survey was 4.3 based on the results of the last three intermediate assessments.

The high academic performance of respondents was justified by the fact that as indicated by the absolute majority of students $(63 \%)$, they did not combine training with work, considering mastering of the educational program the most priority activity at this stage; $21 \%$ 
of respondents noted that they worked to have money for current expenses, while $61 \%$ of respondents got money for current expenses from parents, who also paid their education.

When analyzing the sources for education, it turned out that the family's saving was the main source for $92 \%$ of respondents; while $8 \%$ of respondents indicated that they did not know where their parents got money from to pay for their education. Sources of tuition fees, such as bank loans and maternity capital, were not used at all by the participants involved in the survey.

Most of the respondents (47\%) indicated that when deciding on choosing an educational program, the cost of training and the payment procedure at the Academy satisfied them the most, thus demonstrating a rational consumer approach to purchasing educational services; $39 \%$ of respondents expressed high loyalty to the Academy, noting that they wanted to study at this higher education institution.

The majority of respondents (47\%) also indicated that they hoped to recoup the cost of education during the first five years after graduation, while a significant part of respondents (37\%) were not concerned about it at all, and $16 \%$ of students believed that they did not have any expenses because their parents paid for their education.

When identifying the respondents' knowledge concerning acceptable behaviors in the event of debt for training, $45 \%$ of respondents indicated that they would try to find out in such a situation how to contact the management of the Institute/Academy with a request for an individual schedule of payment for training. However, almost one in three students (34\%) indicated that they would pay for training including accrued penalties when such an opportunity arose that was not a completely rational solution to the problem of lack of funds to pay for training.

In the course of the conducted survey, the basic knowledge and skills in various areas of the financial culture were analyzed. Thus, $50 \%$ of respondents demonstrated the necessary care when concluding financial contracts, indicating that they had read the contract for the provision of paid educational services, knew and controlled the timing of payment. At that, the same percentage of respondents noted that they were familiar with the terms of the contract only in general outline (37\%), while $8 \%$ of students did not read the contract at all.

In matters of money-saving culture, every fifth respondent $(21 \%)$ stated that they did not manage to save money; a significant portion of respondents were trying to make savings but kept money on the card (39\%) or at home in cash (37\%) that was not so safe.

Demonstrating knowledge in the field of financial fraud, almost a third of respondents (29\%) mistakenly indicated a warning of the company that its investments could bring both income and loss as a sign of a financial pyramid, which in practice, on the contrary, rather indicated the trustworthiness of the organization.

Taking into account the responses provided above, the financial topics mentioned by the students most often were quite expected: the most popular issues were financial fraud and security (61\%), taxes (55\%), and investments (47\%).

\section{Discussion}

The data obtained at the first stage of experimental work allow drawing preliminary conclusions about the main elements of the individual financial culture of students and their qualitative characteristics.

The phenomenon of financial culture has a complex multidimensional content, reflects the specifics of the unity of material and spiritual in society at a specific stage of its historical development. This phenomenon includes a set of traditions, norms, and ideas that reflect the level of financial literacy, skills, and behavior of people in the field of financial relations [11]. In the context of the present research, financial culture is considered in a narrow sense as an integral quality of the individual, reflecting knowledge and skills in the field of financial 
activity, financial behavior models, including those learned in the family, as well as individual financial values of the person.

Thus, the conditions and circumstances of students' choice of an educational program that is mastered at the expense of households, as well as their attitude to education as one of the indicators of satisfaction with the consumer choice made, can act as a projection of their independent mature financial behavior and be management objects aimed at forming financially rational attitudes.

Contemporary researchers often include the level of financial literacy in the structure of the financial culture of the population as the main component to be measured $[12,13]$, noting the direct relationship between financial knowledge and the level of general education [14]. Projecting the indicator of financial literacy on the expertise and skills acquired by students during the development of the basic educational programs of higher education in the institutional environment, one can state that the general level of financial knowledge of respondents included in the study sample is quite high that is evidenced by self-assessment of their level of financial literacy and objective indicators of academic performance.

Demonstrated models of financial behavior [15] and financial values are of the greatest interest in the structure of individual financial culture. Thus, the most traditional form of financial behavior of students concerning the development of educational programs at the expense of personal funds of households is a consumer model of behavior which is characterized by a high degree of rationality, as evidenced by the fact that the vast majority of students are not distracted by extraneous activities not related to learning. The program selecting procedure, which, according to the respondents' responses, included preliminary monitoring of similar educational products, also indicates the rational behavior of students as consumers of educational services. At the same time, students act primarily as passive consumers.

Thus, according to the research hypothesis, the involvement of students in thematic volunteer activities in the field of financial literacy and financial control is of special interest, since it can be considered as a quasi-professional activity and a way of informal education [16], allowing students to acquire deeper knowledge and skills in the field of financial culture. The Institute of the Academy of the Federal Penitentiary Service of Russia has been actively cooperating for several years with the regional branch of the Bank of Russia in improving the financial literacy of the population. Students of the Institute of all courses at any stage of their studies at the Institute have the opportunity to master a special program for training financial education volunteers and be engaged in educational volunteering in the field of financial literacy, working with school-age children. However, in the analyzed sample of respondents, only $8 \%$ of the students took advantage of the offered opportunity and gained experience in volunteering, $23 \%$ did not have time for volunteering, while $47 \%$ did not show at all any interest in these activities.

Thus, students are not ready to consider their education as an investment in their human capital, to show any additional activity other than academic activity, and to see the potential for developing their professional skills in the additional nonformal education opportunities offered by the higher education institution.

\section{Conclusion}

Thus, the current article presents the results of just the first stage of the study. The subsequent stages will include a formative experiment to identify management opportunities and change the quality characteristics of the individual financial culture of students. The potential for developing elements of the individual financial culture of students depending on the profile of the educational program, as well as gender aspects of financial patterns and financial behavior of students, are also of scientific interest. 


\section{References}

1. S. Thomas, M. Goel, D. Agrawal, J Of Behav And Experim Fin 26, (2020).

2. C. Strömbäck, T. Lind, K. Skagerlund, D. Västfjäll, G. Tinghög, J Of Behav And Experim Fin 14, 30-38 (2017).

3. K. Leon, C. Pfeifer, J of Behav And Experim Fin 69, 99-107 (2017).

4. S. Krische, A. Mislin, J Of Behav And Exp Fin 87, (2020).

5. X. Li, M. Curran, N. Zhou, J. Serido, S. Shim, H. Cao, J Of Ap Develop Ps 64, (2019).

6. Z. Marjanovic, L. Fiksenbaum, E. Greenglass, J Of Behav And Experim Ec 77, 151-157 (2018).

7. N.Y. Park, Int Rev of Ec \& Fin 67, 408-419 (2020).

8. C. Strömbäck, K. Skagerlund, D. Västfjäll, G. Tinghög, J Of Behav And Experim Fin 27, (2020).

9. Y. Fan, J of Ur Ec 115, (2020).

10. C. Schalck, The Quarterly Review of Economics and Finance 66, 127-135 (2017).

11. A.I. Fatikhov, R.T. Nasibullin, Bulletin of Pacific national university 2(17), 235-244 (2010).

12. S.N. Ilina, V.Yu Stupin, Bulletin of the Baltic Federal University named after I. Kant, Series: Philology, pedagogy, psychology 4, 71-79 (2017).

13. P.J. Morgan, T.Q. Long, J Of As Ec 68, (2020).

14. A. Amagir, W. Groot, H. Maassen van den Brink, A. Wilschut, International Review of Economics Education 34, (2020).

15. A. Alieva, Bulletin of KRSU 16(2), 107-109 (2016).

16. K. Biryukova, Bulletin of the Volgograd State Pedagogical University 10, 18-20 (2020). 